\title{
Morphological study of linea aspera variations: proposal of classification and sexual dimorphism
}

\author{
M. Polguj ${ }^{1}$, K. Bliźniewska' ${ }^{1}$, K. Jędrzejewski², A. Majos³ ${ }^{3}$ M. Topol ${ }^{2}$ \\ ${ }^{1}$ Department of Angiology, Chair of Anatomy, Medical University of Lodz, Lodz, Poland \\ ${ }^{2}$ Department of Normal and Clinical Anatomy, Chair of Anatomy, Medical University of Lodz, Lodz, Poland \\ ${ }^{3}$ Radiology Department, Medical University of Lodz, Lodz, Poland
}

[Received 17 October 2012; Accepted 12 November 2012]

\begin{abstract}
The linea aspera is a roughened, longitudinally oriented, irregular crest composed of two lips located on the posterior surface of the femoral shaft. The purpose of this research was to investigate the morphological variations of the linea aspera in humans. The study was carried out on 90 femurs. Osteometric measurements of the bones were taken using two complementary methods: classical osteometry and a new one based on the analysis of digital photographic documentation of the femur using MultiscanBase v.18.03 software. The analysis allowed four types of linea aspera to be determined: parallel (type I $27.2 \%$ ), concave (type II 25.7\%), convex (type III 5.7\%), and variform (type IV $41.4 \%)$. The frequency of the each type in females and males was also described. A better knowledge of the anatomical variations of the linea aspera may be helpful in orthopaedy and radiology to distinguish pathological from normal anatomical variations. (Folia Morphol 2013; 72, 1: 72-77)
\end{abstract}

Key words: linea aspera, morphological variations, sexual dimorphism

\section{INTRODUCTION}

The linea aspera is the roughened, longitudinally oriented, irregular crest on the posterior surface of the femoral shaft. This structure is composed of two lips - the labium mediale and the labium laterale, which may be separated by up to $10 \mathrm{~mm}[15$, 17]. A rough line divides it distally into medial and lateral supracondylar ridges. Proximally, the lateral lip becomes continuous as the gluteal tuberosity. In rare cases, the most superior part of the gluteal ridge may form a prominent excrescence named the third trochanter [2]. The proximal continuation of the medial lip diverges into two separate lines - the spiral line and the pectineal line. While the spiral line, which provides the origin for the vastus medialis muscle, runs medially towards the lesser trochant- er, the pectineal line, marking the insertion of the pectineus muscle, is located lateral and superior to it [15]. Contrary to this morphological definition, the clinical definition is short, because the linea aspera consists of two axially oriented parallel lines superimposed on the middle third of the posterior surface of the shaft $[5,8,10,17]$. However, according to our observations, the shape of the linea aspera is much more varied and so it is necessary to describe this structure more precisely. Such knowledge may be useful in clinical practice, especially in Radiology and Orthopaedy $[3,7,8,17]$.

According to a search of current literature, no complete photographically documented description exists of linea aspera variations based on both quantitative and qualitative methods. The present study

Address for correspondence: M. Polguj, PhD, MD, Department of Angiology, Chair of Anatomy, Medical University of Lodz, ul. Narutowicza 60, 90-136 Łódź, Poland, tel: +48 4263049 49, e-mail: michal.polguj@umed.lodz.pl 
aims to establish the first quantitative classification of linea aspera morphology which is simple and based on specific geometrical parameters that clearly distinguish each type.

\section{MATERIALS AND METHODS}

A total of 90 human femurs were included in the study (47 left and 43 right). The bones were dated to the second half of the twentieth century (1950s) and originated from the Caucasian population. All investigations were performed in the Chair of Anatomy, the Medical University of Lodz. The osteometric measurements of the femur were carried out according to standard definitions, using procedures and degrees of precision as described elsewhere [14].

The osteometric measurements of the femur were taken directly from the standard anthropometry handbook and used unchanged (Fig. 1) [14]:

1 - greatest femur length;

2 - femoral shaft length;

3 - superior transverse diameter;

4 - femoral head circumference;

5 - femoral head height;

6 - anterior femoral head and neck length;

7 - cervico-corporal angle.

According to the anthropometric rules (Koszelev and Olivier classifications [14]) to determine sexual dimorphism, using the measurements described above, all femurs were divided into three groups: female, male, and non-classified.

For the purpose of the present study, the linea aspera was defined as a prominent longitudinal ridge or crest, localised on the middle third of the posterior surface of the femur, and consisting of medial and lateral lips, and a narrow trough. The term 'ridge' refers to certain measurable features of the structure: the length and width.

Ten measurements precisely describing the linea aspera were taken, the definitions of which were evaluated for the purposes of this study (Fig. 2):

- L1-L9 - nine widths of the linea aspera, defined as the maximum dimension of the measurements, were taken in the horizontal plane in nine different places along its length, between the medial and lateral lips of the linea aspera, which were numbered from L1 to L9. L1 refers to the width of the linea aspera on its proximal onset and $L 9$ refers to its width on its distal ending. The other diameters were taken at equally spaced intervals between these two points. $L 5$ is the width of the linea aspera half way along its length;
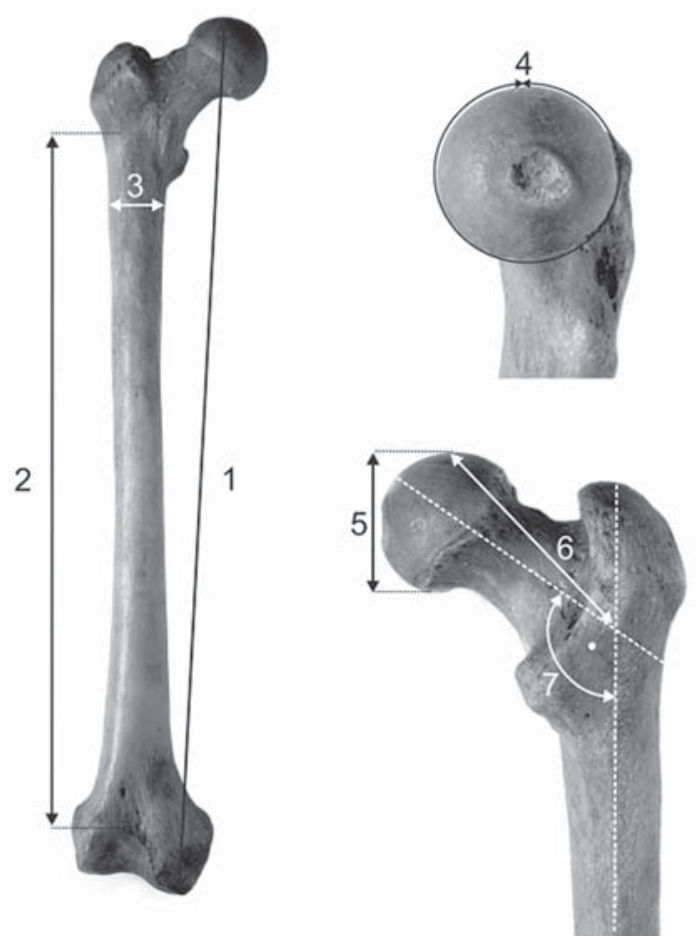

Figure 1. Osteometric measurements of the human femur: 1 greatest femur length; 2 - femoral shaft length; 3 - superior transverse diameter; 4 - femoral head circumference; 5 femoral head height; 6 - anterior femoral head and neck length; 7 - cervico-corporal angle.

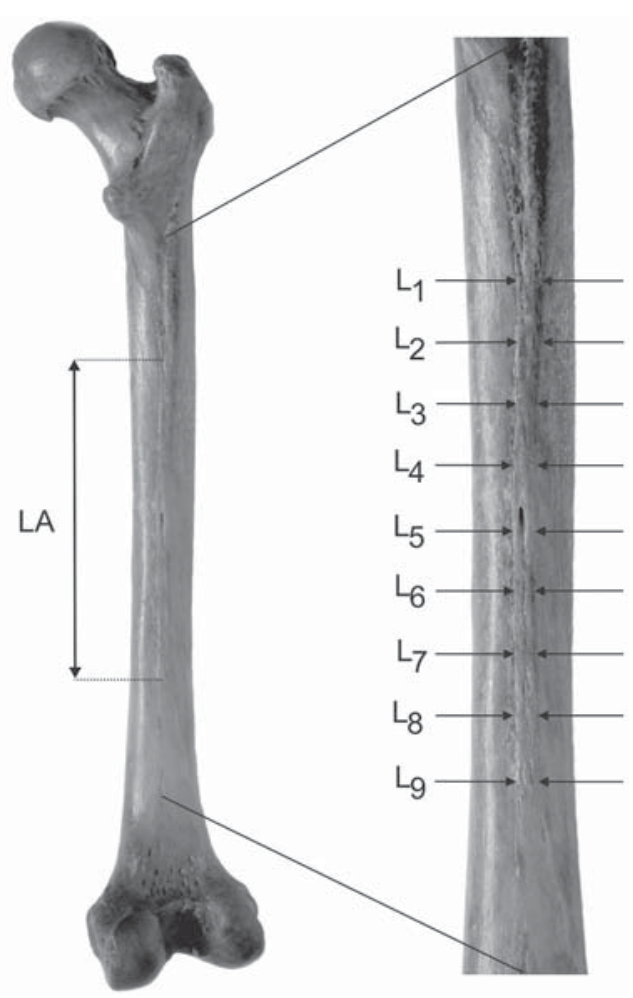

Figure 2. Osteometric measurements of the linea aspera: L1-L9 widths of the linea aspera; LA — length of the linea aspera. 

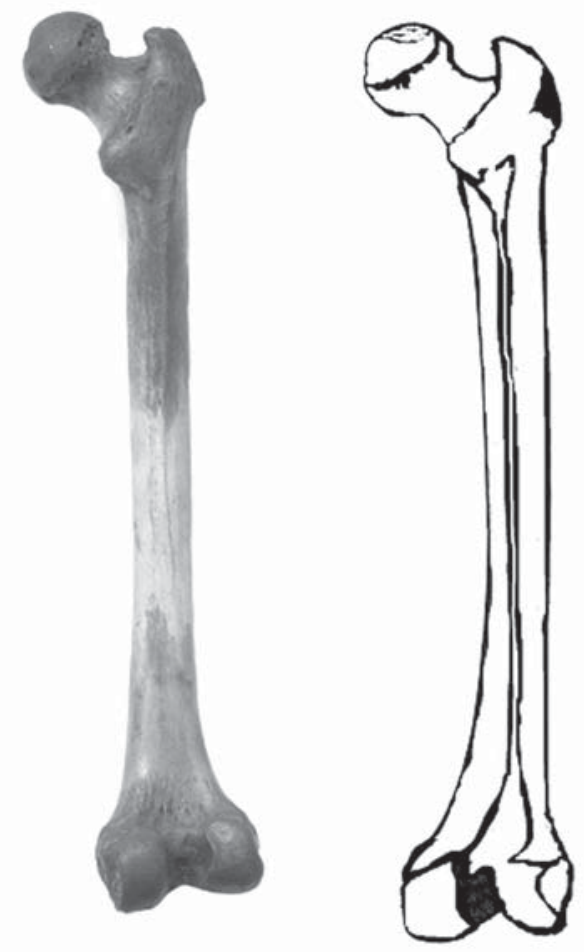

Figure 3. Type I (parallel) of the linea aspera.

- LA - length of the linea aspera, defined as the maximum value of the longitudinal measurements taken in the vertical plane from the proximal end to the distal end of the linea aspera (from L1 to L9).

Detailed measurements of the linea aspera were taken by using two independent methods: the first being a classical anthropometric method using a micrometer digital calliper with an accuracy of $0.05 \mathrm{~mm}$ (Mitutoyo Company, Japan), and the second using digital photographic documentation, which was subsequently analysed using MultiScanBase v. 18.03 software (Computer Scanning System II, Warsaw, Poland). Photographic documentation was collected for every specimen. The photographs were saved in JPEG and TIFF format and later digitally transformed. All measurements of the femur and linea aspera were taken twice by two independent investigators, and the mean of the values was calculated to provide the greatest accuracy. The descriptive statistics used were mean, standard deviation, median, and minimum and maximum for continuous variables.

Data analysis was performed using Statistica 8 software (StatSoft Polska, Cracow, Poland). The distribution of continuous variables was investigated with the Shapiro-Wilk test in order to check whether
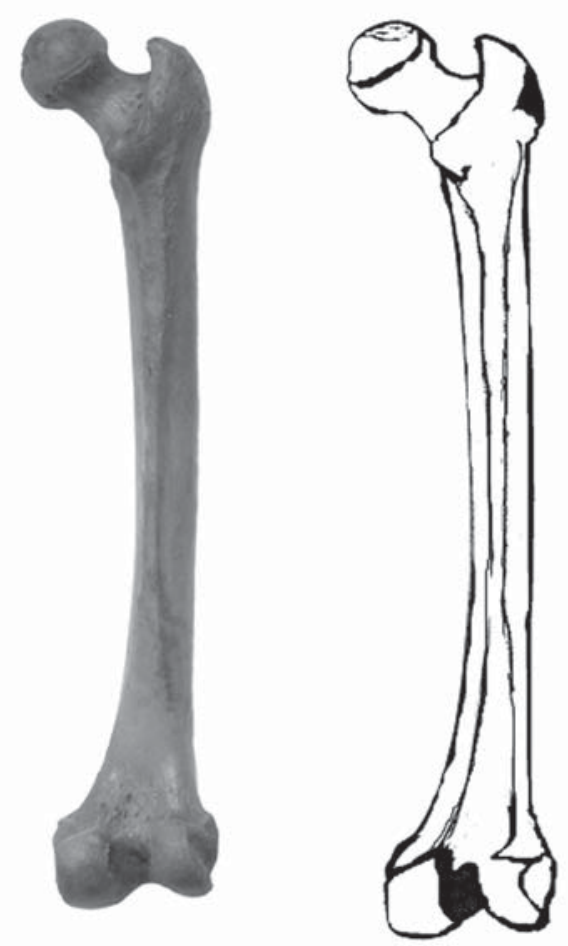

Figure 4. Type II (concave) of the linea aspera.

the distribution was normal or not. The descriptive statistics used were mean and standard deviation for continuous variables. The differences between the measurements in all types of linea aspera were examined using the Mann-Whitney test. A p level of $<0.05$ was accepted as statistically significant.

\section{RESULTS}

Four basic types of linea aspera were noted. In type I (27.2\%) the medial and lateral lips of the linea aspera were parallel to each other (Fig. 3) and all widths of the linea aspera were found to be equal $(\mathrm{L} 1=\mathrm{L} 2=\mathrm{L} 3=\mathrm{L} 4=\mathrm{L} 5=\mathrm{L} 6=\mathrm{L} 7=\mathrm{L} 8=\mathrm{L} 9)$. Type II (25.7\%) had a concave shape (Fig. 4): the widths at the proximal (L1) and distal (L9) ends of the linea aspera were the largest, and the width $L 5$ was the lowest ( $\mathrm{L} 1>\mathrm{L} 2>\mathrm{L} 3>\mathrm{L} 4 \geq \mathrm{L} 5 \leq \mathrm{L} 6<\mathrm{L} 7<\mathrm{L} 8<\mathrm{L} 9)$. In type III $(5.7 \%)$ this shape was inverted - the width at the middle length of the linea aspera (L5) was the largest and the widths at the proximal end (L1) and distal end ( $\mathrm{L9}$ ) were the lowest $(\mathrm{L} 1 \leq \mathrm{L} 2<\mathrm{L} 3<\mathrm{L} 4 \leq \mathrm{L} 5 \geq \mathrm{L} 6>$ $>$ L7 $>$ L8 $\geq$ L9). Macroscopically, the shape of the linea aspera was convex (Fig. 5). Type IV (41.4\%) had a variform shape (Fig. 6). All widths of the linea aspera were different $(\mathrm{L} 1 \neq \mathrm{L} 2 \neq \mathrm{L} 3 \neq \mathrm{L} 4 \neq \mathrm{L} 5 \neq \mathrm{L} 6 \neq \mathrm{L} 7 \neq \mathrm{L} 8 \neq \mathrm{L} 9)$. 

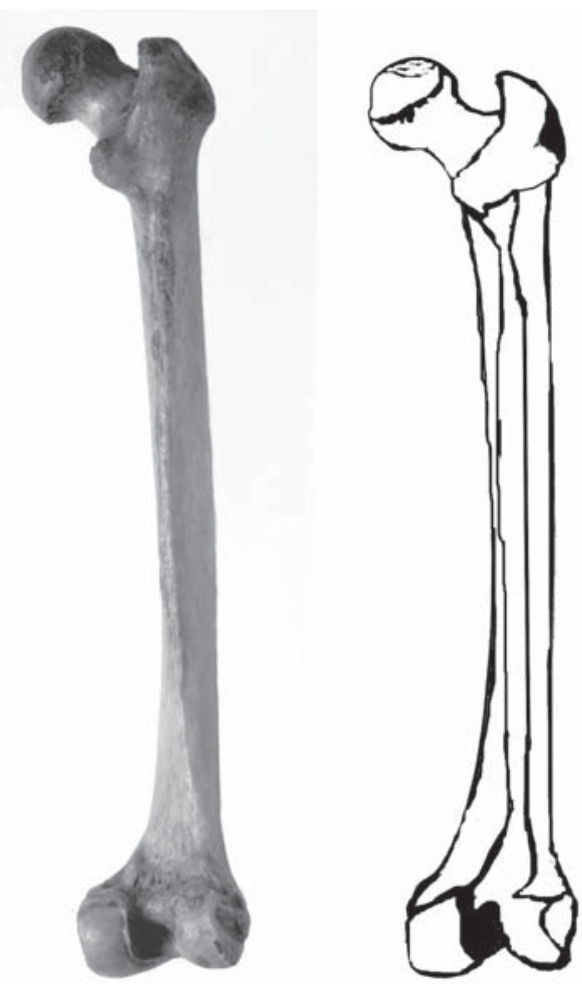

Figure 5. Type III (convex) of the linea aspera.

To incorporate anthropometric rules describing sexual dimorphism of the femur [14], 39 female, 40 male, and 11 non-classified bones were distinguished. With regard to sex differences, the most common type of linea aspera was the type IV variform ( $41 \%$ in men and $39 \%$ in women) in both groups. In men, the second and third most common types were the type II - concave $(31 \%)$ and type I - parallel $(22 \%)$. However, in women this order was reversed - type I (parallel) was second (32\%) and type II (concave) was third (23\%). Type III (convex) was the least common in both groups $(6 \%$ of male and $6 \%$ of female). The anthropometric measurements of the femurs collected in the study in female and male are presented in Table 1.

The mean length of the concave-shaped linea aspera $(195.3 \pm 35.9 \mathrm{~mm})$ was higher than that of those with variform (189.9 $\pm 40.1 \mathrm{~mm})$, convex (184.8 \pm $\pm 55.3 \mathrm{~mm})$, and parallel $(181.4 \pm 34.2 \mathrm{~mm})$ shapes (Table 2). However, this difference was statistically insignificant according the Mann-Whitney test $(p<0.05)$.

\section{DISCUSSION}

The linea aspera is one of several "qualitative features" describing the human body $[12,13]$. Other

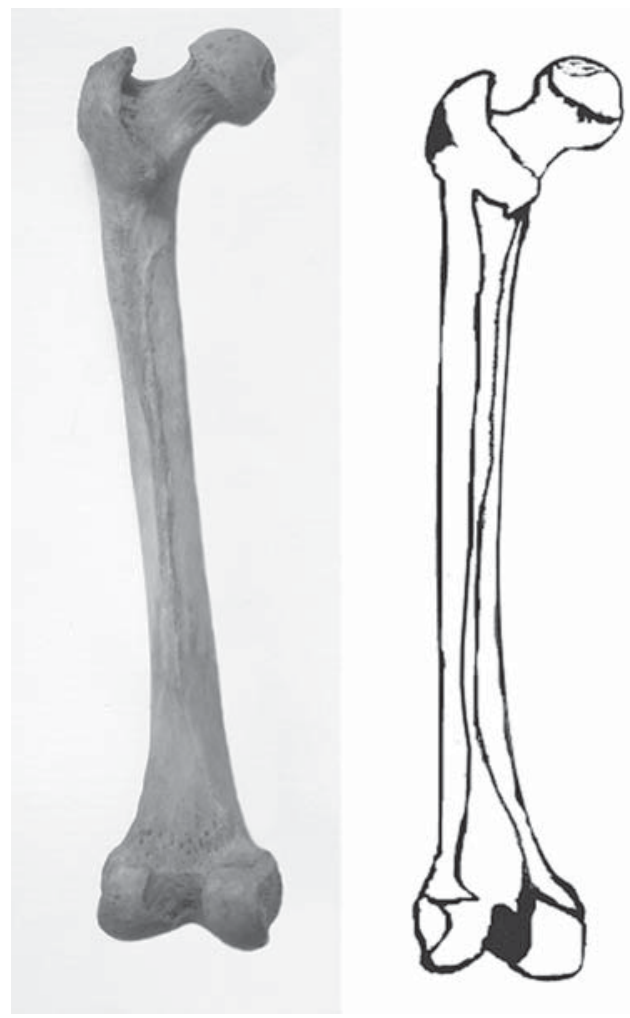

Figure 6. Type IV (variform) of the linea aspera.

features, which have been much better described, include the third trochanter $[2,11]$ or suprascapular notch [20,22].

One of the most probable explanations of the function of the linea aspera is that both of the lips of the rough line serve for the insertion of strong adductor and extensor muscles such as the musculus adductor longus, musculus adductor brevis, musculus adductor magnus, musculus vastus medialis, and musculus vastus lateralis. Hence, its development would be the consequence of a relative strengthening of those muscles in humans in comparison to other primates $[11,12]$. Additionally, the linea aspera may work as a resistance pole that can stiffen the femur within its forward prominence. It is frequently elevated by an underlying bony ridge, resulting in a prismatic, cross-sectional configuration [13].

Also, Pauwels [16] states that the main functions of the linea aspera are stabilisation and support for the femur, especially while walking and running. The linea aspera may be a feature that helped our species to extend its sphere of influence. The prominent development of the linea aspera is a distinctly human feature not seen in lower primates $[11,12]$. Thanks to the above-described 
Table 1. The comparison of osteometric measurements of the femurs in females and males

\begin{tabular}{lccccccc}
\hline Measurements & \multicolumn{3}{c}{ Female } & & \multicolumn{3}{c}{ Male } \\
\cline { 2 - 4 } \cline { 7 - 8 } & Mean \pm SD & Median & Min.-Max. & & Mean \pm SD & Median & Min.-Max. \\
\hline Greatest femur length [mm] & $421.1 \pm 33.7$ & 421 & $359-508$ & & $456.3 \pm 27.3$ & 457 & $370-514$ \\
Femoral shaft length [mm] & $328.3 \pm 28.1$ & 327 & $285-392$ & & $355.8 \pm 26.7$ & 352.5 & $289-422$ \\
Superior transverse diameter [mm] & $32.5 \pm 2.3$ & 32.1 & $27.3-39$ & & $33.1 \pm 1.9$ & 32.7 & $29.4-37$ \\
Femoral head circumference [mm] & $138.2 \pm 10.2$ & 140 & $118-156$ & & $149.3 \pm 9.6$ & 150.5 & $129-163$ \\
Femoral head height [mm] & $40.9 \pm 4.9$ & 42.1 & $31-49.2$ & & $43.7 \pm 4.1$ & 44 & $37-51$ \\
Anterior femoral head and neck length [mm] & $69.6 \pm 4.1$ & 69.1 & $53-78.9$ & & $71.4 \pm 4.3$ & 69.8 & $66.9-82$ \\
Cervico-corporal angle $\left[^{\circ}\right]$ & $118.6 \pm 2.9$ & 119.5 & $109-126$ & & $130.3 \pm 2.6$ & 130 & $127-136$ \\
\hline
\end{tabular}

Table 2. The comparison of lengths of the linea aspera in its different morphologies [mm]

\begin{tabular}{lcccc}
\hline & Type I (parallel) & Type II (concave) & Type III (convex) & Type IV (variform) \\
\hline Mean & 181.4 & 195.3 & 184.8 & 189.9 \\
Standard deviation & 34.2 & 35.9 & 55.3 & 40.1 \\
Median & 182 & 195 & 184.5 & 190 \\
Min.-Max. & $118-261$ & $150-270$ & $130-240$ & $128-270$ \\
\hline
\end{tabular}

functions, the linea aspera would appear to be a form of adaptation to a bipedal gait pattern [13], as confirmed by Beauval et al. [1]. A further study addressed the morphology of the linea aspera on Neanderthal femurs, in which both lips of the linea aspera were seen to form a soft crest. Pleistocene modern human femurs also tend to have teardrop shaped cross-sections, prominent pilasters, and flat or especially concave surfaces adjacent to the linea aspera [23]. The pilaster also provides the additional biomechemical support for the posterior femur. In rachitis, insufficient calcification may lead to osteomalacia, in which, as a result of loading, the femoral forward prominence can increase significantly, the bone can be flattened to one side, and the linea aspera can change into a narrow ridge known as the stenometry [11].

The topography of the linea aspera is an important factor in some surgical techniques, such as in the posterior approach of the femur [3] or in the modified transfemoral approach [7]. It is a crucial area for fat embolism protection during cemented total hip arthroplasty. In this example, drainage of the venous system located along the linea aspera significantly reduces the risk of intraoperative embolism and cardiopulmonary impairment $[18,19]$. Similarly, Draenert [6] report that an increase in the intramedullary pressure can lead to embolisation of bone marrow contents via the venous drainage system along the linea aspera.

An important piece of topographic information for Orthopaedics and surgery is that the principal nutrient foramina of the femur are located in the linea aspera with possible variations in number and position [9]. Colipal et al. [4] discovered that the nutrient foramina of the femur was located in the linea aspera in $72.5 \%$ of specimens: $36.25 \%$ in the interstice, $8.75 \%$ in the lateral lip, and $27.5 \%$ in the medial lip of the linea aspera. Also Yamamoto et al. [24] note that either one or two nutrient vessels of a large calibre originating from the perforating branches of the profunda femoris artery enter at a number of points along the linea aspera of the femur. Such awareness of the terminal courses of arteries may be useful in performing operations, by minimizing the risk of bleeding.

The prominent development of the linea aspera is visible on frontal and anteroposterior radiographs of the femur mainly in adults and, in some cases, adolescents as two thin, axially-oriented, parallel lines [17]. Pitt [17] named it the "track sign" and proposed that it represents the linea aspera-pilaster complex. Hoeffel et al. [10] assert that knowledge of the shape of the normal linea aspera is important 
and should not be confused with diseases such as symmetrical osteonecrosis. Also, Gheorghiu and Leinenkugel [8] noted that the "track sign" can be readily confused with the pathological "flame sign" of Paget's disease leading to unnecessary investigations. Pitt [17] concluded that normal morphological variants should be well known, especially to orthopaedic surgeons and radiologists. This is confirmed by Seeger et al. [21] who described a tumoral calcinosis-like growth located along the proximal part of the linea aspera, probably formed by the lesion of this part of the bone, which may be mistaken for some variations of the linea aspera. Therefore, knowledge of morphological variations is essential to form an appropriate clinical diagnosis.

Thanks to two techniques used for measuring and typing the linea aspera our investigation has very precisely classified variations of this structure. It has also, for the first time, explicitly demonstrated types of linea aspera in females and males. To our knowledge, no similar study exists in the literature.

\section{CONCLUSIONS}

The present study aims to establish the first quantitative classification of the linea aspera, which is simple to apply, being based on specific geometrical parameters and its morphology. The two methods used for measuring were complementary and could be used to better analyse the fine details. The classification we present may be helpful in orthopaedic open procedures of the posterior femoral region, as well as in diagnostic radiological procedures to distinguish pathology from anatomical variations.

\section{REFERENCES}

1. Beauval $C$, Maureille $B$, Lacrampe-Cuyaubère $F$, Serre $D$, Peressinotto D, Bordes JG, Cochard D, Couchoud I, Dubrasquet D, Laroulandie V, Lenoble A, Mallye JB, Pasty S, Primault J, Rohland N, Pääbo S, Trinkaus E (2005) A late Neandertal femur from Les Rochers-de-Villeneuve France. Proc Natl Acad Sci, 102: 7085-790.

2. Bolanowski W, Śmiszkiewicz-Skwarska A, Polguj M, Jędrzejewski KS (2005) The occurrence of the third trochanter and its correlation to certain anthropometric parameters of the human femur. Folia Morphol, 64: 168-175.

3. Bosworth DM (1944) Posterior approach of the femur. J Bone Joint Surg Am, 26: 687-690.

4. Collipal E, Vargas R, Parra X, Silva H, del Sol M (2007) Forámenes Nutricios Diafisarios de los Huesos Fémur, Tibia, Fíbula. Int J Morphol, 25: 305-308.

5. Desai SC, Willson S (1985) Radiology of the linea aspera. Australian Radiol, 29: 273-274.
6. Draenert K (1989) Modern cementing techniques. An experimental study of vacuum insertion of bone cement. Acta Orthop Belg, 55: 273-293.

7. Fink B, Grossmann A (2007) Modified transfemoral approach to revision arthroplasty with uncemented modular revision stems. Oper Orthop Traumatol, 19: 32-55.

8. Gheorghiu D, Leinenkugel A (2010) The linea asperapilaster complex as a possible cause of confusion with the "flame sign': a case report. Acta Orthop Traumatol Turc, 44: 254-256.

9. Gumusburun E, Yucel F, Ozkan Y, Akgun Z (1994) A study of the nutrient foramina of lower limb long bones. Surg Radiol Anat, 16: 409-412.

10. Hoeffel C, Munier G, Hoeffel JC (1993) The femoral linea aspera: radiological pattern. Eur Radiol, 3: 357-358.

11. Hrdlica A (1934) The gluteal ridge and gluteal tuberosities (3 ${ }^{\text {rd }}$ trochanter). Am J Phys Antropol, 23: 127-198.

12. Loth $\mathrm{E}$ (1955) Odmiany mammalogeniczne $w$ budowie człowieka. Przegl Antrop, 21: 258-280.

13. Loth $E$ (1957) Cechy eugeniczne w budowie człowieka. Przegl Antrop, 23: 259-312.

14. Malinowski A, Bożiłow W (1997) Podstawy antropometrii: metody, techniki, normy. Wydawnictwo Naukowe PWN, Warszawa-Łódź.

15. Moroe K, Dalley A (2006) Clinically oriented anatomy. Lippincott Wiliams \& Wilkins, Philadelphia.

16. Pauwels $F(1954)$ The static significance of linea aspera; fourth contribution to the functional anatomy and causal morphology of the supporting apparatus. Z Anat Entwicklungsgesch, 117: 497-503.

17. Pitt MJ (1982) Radiology of the femoral linea asperapilaster complex: the track sign. Radiology, 142: 66.

18. Pitto RP, Schramm M, Hohmann D, Kössler M (1999) Relevance of the drainage along the linea aspera for the reduction of fat embolism during cemented total hip arthoplasty, Arch Orthop Trauma Surg, 119: 146-150.

19. Pitto RP, Koessler M, Kuehle JW (1999) Comparison of fixation of the femoral component without cement and fixation with use of a bone-vacuum cementing technique for the prevention of fat embolism during total hip arthroplasty. A prospective, randomized clinical trial. J Bone Joint Surg Am, 81: 831-843.

20. Sinkeet SR, Awori KO, Odula PO, Ogeng JA, Mwachaka PM (2010) The suprascapular notch: its morphology and distance from the glenoid cavity in a Kenyan population. Folia Morphol, 69: 241-245.

21. Seeger LL, Butler DL, Eckardt JJ, Layfield L, Adams JS (1990) Tumoral calcinosis-like lesion of the proximal linea aspera. Skeletal Radiol, 19: 579-583.

22. Ticker JB, Djurasovic M, Strauch RJ, April EW, Pollock RG, Flatow EL, Bigliani LU (1998) The incidence of ganglion cysts and other variations in anatomy along the course of the suprascapular nerve. J Shoulder Elbow Surg, 7: 472-478.

23. Trinkaus E, Ruff CB (1999) Diaphyseal Cross-sectional geometry of Near Eastern middle palaeolithic humans: the femur. J Archaeol Sci, 26: 409-424.

24. Yamamoto Y, Ohura T, Sugihara T (1995) An anatomic study for a vascularized bone flap of femur. Plast Reconstr Surg, 95: 520-555. 